\title{
Supplemental effects of diet mixing on absorption of ingested organic carbon in the marine copepod Acartia tonsa
}

\author{
Peter Thor ${ }^{1, *}$, Marja Koski $^{2}$, Kam W. Tang ${ }^{2,3}$, Sigrún H. Jónasdóttir ${ }^{2}$ \\ ${ }^{1}$ Göteborg University, Department of Marine Ecology, Kristineberg Marine Research Station, 45034 Fiskebäckskil, Sweden \\ ${ }^{2}$ Danish Institute for Fisheries Research, Department of Marine Ecology and Aquaculture, Kavalergården 6, \\ 2920 Charlottenlund, Denmark \\ ${ }^{3}$ Virginia Institute of Marine Science, Rt. 1208, Greate Road, Gloucester Point, Virginia 23062-1346, USA
}

\begin{abstract}
We investigated increased carbon absorption efficiencies (AEs) as a possible cause for positive effects of diet mixing on copepod egg production rates (EPRs) and hatching success (EHS). Female Acartia tonsa were fed ${ }^{14} \mathrm{C} /{ }^{51} \mathrm{Cr}$ dual-labelled Dunaliella tertiolecta (Dun), Amphidinium carterae (Amp), Phaeocystis globosa (Pha), and 3 pairwise 1:1 mixes of the 3 diets. AEs, derived from the ratios of labels in algae and copepod faecal pellets, were $44 \%$ on Dun, $37 \%$ on Amp, and $49 \%$ on Pha, but increased significantly to $61 \%$ on Dun + Amp. As a result, EPRs remained low in all tested diets except for Dun + Amp, where it was twice that in the individual diets. Linear multiple regression analysis revealed that EPRs were strongly dependent on the ingestion and absorption of the fatty acids 18:3(n-3) and 22:6(n-3) so that the simultaneous ingestion and absorption of 18:3(n-3) from Dun and 22:6(n-3) from Amp enhanced EPR in the Dun + Amp diet. EHS was low with the Dun diet, which was devoid of 20:5(n-3) and 22:6(n-3). Multiple regression analysis showed that EHS depended on $16: 1(n-7)$ and any or all of 22:6(n-3), 20:5(n-3), or 18:5(n-3).
\end{abstract}

KEY WORDS: Copepods $\cdot$ Food quality $\cdot$ Absorption efficiency $\cdot$ Diet mixing $\cdot$ Fatty acid composition Resale or republication not permitted without written consent of the publisher

\section{INTRODUCTION}

Copepod secondary production is constrained not only by the availability of plankton prey but also by the nutritional quality of the prey. The nutritional composition of the available food is of paramount importance to growth and egg production, and when the species composition of the phytoplankton community fluctuates so does copepod production. The composition of essential nutritional compounds such as fatty acids and amino acids differ considerably among algal species (Jónasdóttir 1994, Kleppel et al. 1998), and copepods may accordingly optimise the nutritional intake through behavioral adaptation of feeding activity. This is possible not only through selective grazing on good quality prey containing all essential nutritional compounds. During periods when poor quality phyto- plankton species predominate, as for instance during summer in temperate waters, high copepod production may be sustained by combined ingestion of different phytoplankton species. During these periods, when food quality limits growth and production, diet mixing increases the probability of a nutritionally balanced food intake and consequently higher growth (Kleppel \& Burkart 1995).

Previous studies have shown that differences in prey quality induce differences in copepod egg production, longevity, and population development (Schmidt \& Jónasdóttir 1997, Payne \& Rippingale 2000, Rey et al. 2001, Shin et al. 2003). These differences often arise from varying gross growth efficiencies (GGE) (Rey et al. 2001) not only due to differences between monospecific diets but also due to diet mixing (Kleppel \& Burkart 1995). 
Since, in terms of carbon:

and

$$
d=g+r+u
$$

$$
\text { GGE }=\frac{g}{i}
$$

where $d$ is the rate of carbon absorption in the gut, $g$ is growth rate, $r$ is respiration rate, $u$ is excretion rate, and $i$ is ingestion rate, it follows that:

and

$$
g=d-(r+u)
$$

$$
\mathrm{GGE}=\frac{d-(r+u)}{i}
$$

Increased growth rates or GGE are therefore caused either by lower respiration rates, lower excretion rates, higher absorption rates, or a combination of these, at any given ingestion rate. Respiration is strictly coupled to biosynthesis (Thor 2000) and earlier studies have shown increased rather than decreased respiration rates in copepods feeding on good quality diets as opposed to poor quality diets (Thor et al. 2002). Furthermore, excretion rates of carbon (urea) are very low compared to respiration and egg production rates (Miller \& Glibert 1998), and we therefore predict that any enhancing effects of diet mixing may be caused by increased absorption rates in the copepod gut. The objective of the study was therefore to investigate the effect of diet mixing on the efficiency and rate of absorption of ingested carbon and how this affects egg production in Acartia tonsa. The chlorophyte Dunaliella tertiolecta, the dinoflagellate Amphidinium carterae and the prymnesiophyte Phaeocystis globosa were chosen as poor quality diets. Previously, these phytoplankton species have been reported to induce low rates of growth and reproduction in marine copepods (Støttrup \& Jensen 1990, Koski et al. 1998, Tang et al. 2001).

The term assimilation has previously been erroneously used to describe the uptake of nutrients in the gut (Calow \& Fletcher 1972). In the present paper, we use the term absorption. For the fraction of ingested carbon absorbed we use the term absorption efficiency (AE) which can be conveniently measured by comparing rates of ingestion (i) and egestion (e):

$$
\mathrm{AE}=\frac{d}{i}=\frac{1-e}{i}
$$

Unless otherwise noted in the text, we compare only with previous studies measuring absorption efficiency and not assimilation efficiency (in its true meaning), regardless of what term has been used in those studies.

\section{MATERIALS AND METHODS}

Acartia tonsa were reared in culture at Kristineberg Marine Biological Station, Sweden, at $18^{\circ} \mathrm{C}$ in $0.3 \mu \mathrm{m}$ filtered seawater (34 PSU) under indirect natural light conditions. The copepods were sustained on a diet consisting mainly of a mixture of Thalassiosira weissflogii, Rhodomonas baltica, Tetraselmis impellucida, and Isochrysis galbana.

Dunaliella tertiolecta, Amphidinium carterae and Phaeocystis globosa were cultured in 34 PSU $0.3 \mu \mathrm{m}$ filtered and autoclaved seawater at $18^{\circ} \mathrm{C}$ at a light: dark cycle of 14:10 h. The seawater was enriched with $f / 2$ growth medium for $D$. tertiolecta and A. carterae and $L 1$ medium for P. globosa (Guillard 1975), the latter with gentle bubbling. P. globosa were filtered through a $30 \mu \mathrm{m}$ mesh prior to all experiments to exclude colonies.

Prior to all experiments the copepods were acclimatised in $1000 \mathrm{ml}$ glass bottles to the experimental diets at a total algal concentration corresponding to $150 \mu \mathrm{g} \mathrm{C}$ $\mathrm{l}^{-1}$ for $48 \mathrm{~h}$ on a rotating plankton wheel $(0.5 \mathrm{rpm})$ to allow the copepods to adjust to the experimental food type and concentration.

Ingestion rates, egg production rates, and egg hatching success. Six different diets at a total concentration corresponding to $\sim 150 \mu \mathrm{g} \mathrm{C} \mathrm{l}^{-1}$ were prepared. These were Dunaliella tertiolecta (Dun), Amphidinium carterae (Amp), Phaeocystis globosa (Pha), D. tertiolecta + A. carterae $($ Dun $+A m p)$, D. tertiolecta $+P$. globosa (Dun + Pha), and A. carterae + P. globosa (Amp $+P h a)$. The mixed diets were prepared as 1:1 mixtures on a carbon concentration basis. Replicate $20 \mathrm{ml}$ samples ( $\mathrm{n}=3$ or 4 ) were fixed with Lugol's solution for measurements of initial algal cell concentrations. Replicates ( $\mathrm{n}=3$ or 4 ) of each algal mixture were prepared in $1000 \mathrm{ml}$ glass bottles and 30 Acartia tonsa females were added. Likewise replicate controls $(n=3$ or 4) without copepods were prepared. All bottles were incubated for 12 to $20 \mathrm{~h}$ in dim light conditions on the plankton wheel $(0.5 \mathrm{rpm})$. After the incubation, $20 \mathrm{ml}$ samples were fixed in Lugol's solution for measurements of final algal cell concentrations. Copepod eggs were filtered onto a $30 \mu \mathrm{m}$ mesh and counted under the dissecting microscope.

Ingestion rates (IR) were measured from the disappearance of particles in the bottles containing copepods compared to the control bottles (Frost 1972). The cell concentrations of the initial and final algal samples were counted using an Elzone 5380 electronic particle counter in the 2 to $12 \mu \mathrm{m}$ particle size range. This size range was used to avoid false counts due to larger debris in the water. For the mixed diets, numbers of cells of the 2 algal species were estimated separately by fitting 2 normal distribution curves to the twopeaked size frequency distribution output from the particle counter. The fit giving the best correlation between the size frequency distribution output and the sum of the 2 normal distribution curves was chosen by 
iteration. The correlation coefficients (r) of these fits were never below 0.98. Algal carbon contents were estimated from several measurements of cell volume with the particle counter using an average volume-tocarbon conversion regression for non-diatom phytoplankton (Montagnes et al. 1994). The calculated weights were $17.1 \pm 3.1 \mathrm{pg} \mathrm{C}^{-1} \mathrm{cell}^{-1}$ for Dunaliella tertiolecta, $37.3 \pm 13.0 \mathrm{pg} \mathrm{C}$ cell $^{-1}$ for Amphidinium carterae, and $7.97 \pm 2.06 \mathrm{pgC} \mathrm{cell}^{-1}$ for Phaeocystis globosa.

Egg production rates (EPR) were calculated from the total number of eggs produced during the incubation period. Carbon specific rates were estimated using a

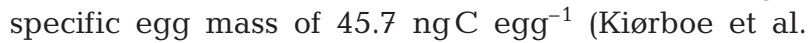
1985). Produced eggs were kept in petri dishes at the experimental temperature for $48 \mathrm{~h}$ and hatched nauplii and unhatched eggs were counted to calculate egg hatching success (EHS). Gross growth efficiencies (GGE) were calculated as EPR/IR $\times 100 \%$.

Ten copepods from each experiment were treated with $4 \%$ formaldehyde, frozen and analysed for carbon weight using high temperature combustion. Rates of ingestion and egg production were normalized to the copepod's body carbon weight.

Absorption efficiencies. Absorption efficiency (AE) was measured using a dual tracer technique with ${ }^{14} \mathrm{C}$ as the absorbable tracer and ${ }^{51} \mathrm{Cr}$ as the inert tracer (Calow \& Fletcher 1972). Dunaliella tertiolecta, Amphidinium carterae, and Phaeocystis globosa were incubated with $500 \mu \mathrm{Ci} \mathrm{NaH}{ }^{14} \mathrm{CO}_{3} \mathrm{l}^{-1}$ and grown for at least 5 cell divisions prior to the experiments to ensure uniform labelling. One day before the experiments $100 \mu \mathrm{Ci}{ }^{51} \mathrm{CrCl}_{3} \mathrm{l}^{-1}$ were added. The ${ }^{51} \mathrm{Cr}^{3+}$ was kept dissolved in $0.5 \mathrm{M} \mathrm{HCl}$ in the stock solution. When introduced into the algal culture medium $(\mathrm{pH} \sim 8.5)$ the ${ }^{51} \mathrm{Cr}^{3+}$ adsorbs to particles. Prior to the incubations with copepods, the labelled algae were rinsed by centrifugation and resuspending in $0.3 \mu \mathrm{m}$ filtered seawater. The centrifugal force was chosen so that algal cells were alive and motile after the process. $D$. tertiolecta were centrifuged at $500 \times g$ for $5 \mathrm{~min}$ and A. carterae and P. globosa at $1000 \times g$ for $5 \mathrm{~min}$. As a further precaution, after one experiment it was ensured that all 3 algal cultures grew well after the centrifugation process.

Algal mixtures were prepared as for the IR and EPR measurements from the labelled algal stocks. Samples of 200 to $500 \mathrm{ml}$ from these mixtures were fixed in Lugol's solution. Replicate $10 \mathrm{ml}$ subsamples $(\mathrm{n}=5)$ were filtered onto GF/F filters and the isotopic activities were measured by liquid scintillation counting (Beckman LS5000TD liquid scintillation counter). Auger electrons $(4.5 \mathrm{keV})$ and X-rays $(5 \mathrm{keV})$ from ${ }^{51} \mathrm{Cr}$ was counted from channel 0 to 270 and $\beta$-electrons from ${ }^{14} \mathrm{C}$ (156 keV) were counted from channel 270 to 1000 on the liquid scintillation counter (cf. Sheppard \&
Marlow 1971), both corrected for counting efficiencies and quenching. As for the IR and EPR measurements, 3 or 4 replicates of each algal mixture were prepared in $1000 \mathrm{ml}$ glass bottles, 30 copepods were added, and the bottles were incubated for $6 \mathrm{hr}$ in dim light conditions on the plankton wheel. Subsequently, faecal pellets were filtered onto a $30 \mu \mathrm{m}$ mesh, washed with $0.3 \mu \mathrm{m}$ filtered seawater 3 times, and rinsed into petri dishes. All intact faecal pellets were carefully mouth pipetted into scintillation vials using drawn Pasteur pipettes. Isotopic activity of the faecal pellets was measured as above. AEs were calculated as:

$$
\mathrm{AE}=\left(1-\frac{R_{\text {faeces }}}{R_{\text {algae }}}\right) \times 100 \%
$$

where $R_{\text {faeces }}$ and $R_{\text {algae }}$ are the ratios between the isotopic activities of ${ }^{14} \mathrm{C}$ and ${ }^{51} \mathrm{Cr}$ in faecal pellets and algae. Absorption rates (AR) were calculated as IR $\times$ AE.

Fatty acid composition. Approximately $20 \mathrm{ml}$ of each algal culture was filtered onto pre-combusted $\mathrm{GF} / \mathrm{F}$ filters. The filters were frozen at $-80^{\circ} \mathrm{C}$ and stored for fatty acid composition analysis by gas chromatography. Lipids were extracted by ultrasound into $\mathrm{CH}_{2} \mathrm{Cl}_{2}$-methanol $(2: 1 \mathrm{v} / \mathrm{v})$ and the fatty acids transmethylated with $\mathrm{BF}_{3}$-methanol to form fatty acid methyl esters (FAME). Identification of fatty acids was accomplished by comparison with retention times of several FAME standards: Larodan PUFA, fatty acid from the dinoflagellate Prorocentrum mimimum to locate 18:5(n-3), Matreya PUFA3, and Supelco FAME mix 18919.

Statistics. IRs, EPRs, and AEs were compared between diets by ANCOVA with algal concentration as the covariate. This approach was chosen since algal concentrations were not entirely equal between experiments (Table 1). Subsequent Bonferroni post-hoc tests were used to test for differences between specific diets.

Table 1. Algal concentrations in the different experiments: absorption efficiency experiments (AE), ingestion rate experiments (IR), and egg production rate experiments (EPR) in $\mu \mathrm{gC}^{-1}$. Dun $=$ Dunaliella tertiolecta, Amp $=$ Amphidinium Carterae, Pha $=$ Phaeocystis globosa. Dun + Amp, Dun + Pha, and $A m p+P h a$ denote mixed diets. Numbers are means \pm SD of 3 or 4 replicates

\begin{tabular}{|lcccc|}
\hline Diet & \multicolumn{2}{c}{ AE } & \multicolumn{2}{c|}{ IR \& EPR } \\
\hline Dun & 137 & \pm 15 & 173 & \pm 1 \\
Amp & 230 & \pm 13 & 142 & \pm 57 \\
Pha & 202 & \pm 20 & 168 & \pm 44 \\
Dun + Amp & 183 & \pm 1 & 151 & \pm 17 \\
Dun + Pha & 169 & \pm 17 & 151 & \pm 19 \\
Amp + Pha & 216 & \pm 5 & 162 & \pm 2 \\
\hline
\end{tabular}


To test whether overall carbon ingestion and the fatty acid composition of the diet could explain variations in EPR and EHS we calculated IRs of specific fatty acids on all diets from the fraction of individual fatty acids and the carbon ingestion rates assuming that total fatty acids constitute $13 \%$ of the carbon mass of algal cells (Arendt et al. 2005). Likewise, to test the extent to which variations in EPR could be explained by the overall carbon AE and fatty acid composition of the diet we calculated estimated absorption rates (ARs) of specific fatty acids as IR of the fatty acids $\times$ AE. These ARs are an approximation since they do not explain the actual absorption rates of specific fatty acids. IRs of specific fatty acids were compared using Pearson product moments correlation analysis. EPRs and EHS were compared to IRs and ARs of specific fatty acids by linear multiple regression analysis.

\section{RESULTS}

\section{Ingestion rates, egg production rates, and egg hatching success}

Ingestion rates, egg production rates, and egg hatching success on the 6 diets are shown in Table 2. There were no significant differences in IR between diets (1-factor ANCOVA: $F_{5,11}=3.122, \mathrm{p}=0.054$ ) but the power of the test was only 0.477 so the negative result should be interpreted cautiously. From the data it is obvious that any differences would arise from the lower ingestion rates on the Dun diet. EPRs were significantly different between diets (1-factor ANCOVA: $\left.F_{5,26}=7.23, \mathrm{p}<0.001\right)$. This difference was caused by significantly higher EPRs on the Dun + Amp diet (Bonferroni post hoc test: $\mathrm{p}<0.0001$ ). On the other hand, EPRs in the Dun + Pha and Amp + Pha treatments were not significantly different from those in the corresponding monospecific diet treatments. Gross growth efficiencies (GGEs) averaged $37 \%$ for Dun + Amp, whereas it was below $25 \%$ on all other diets (Table 2). EHS were significantly different (1-factor ANOVA: $F_{5,13}=24.8, p<0.001$ ) due to the low hatching success of eggs produced on the Dun diet (Bonferroni post-hoc test: $\mathrm{p}<0.001$ ) (Table 2). Algal cell concentrations were lowered by 20-30\% during incubations so we are confident with the IR measurements.

\section{Absorption efficiencies}

Diets had significant effects on AEs (Table 2; 1-factor ANCOVA on arcsine-square root transformed AEs: $\left.F_{5,12}=182.9, \mathrm{p}<0.001\right)$. The AE of the Dun + Amp diet was significantly higher than on both monospecific diets (Bonferroni post-hoc test: $\mathrm{p}<0.001$ ). This enhancing effect was not seen with the 2 other mixed diets: Dun + Pha induced lower and Amp + Pha unchanged AEs. The absorption rate (IR $\times$ AE) increased more than 3-fold on Dun + Amp compared to the corresponding monospecific diets (Table 2).

\section{Relationship between ingestion and absorption of fatty acids, and EPR or EHS}

The fatty acid composition was different between the 3 algal species (Fig. 1). There was extensive intercorrelation between the IRs of the different fatty acids (Pearson product moment analysis, $\mathrm{p}<0.05$ ) with 3 distinct intracorrelating groups:

Table 2. Acartia tonsa. Ingestion rates (IR), absorption efficiencies (AE), absorption rates (AR), egg production rates (EPR), gross growth efficiencies (GGE), and egg hatching success (EHS) of A. tonsa fed 6 different algal diets. See Table 1 for abbreviations of diets. Numbers are mean \pm SD of 3 to 4 replicates

\begin{tabular}{|c|c|c|c|c|c|c|c|}
\hline Diet & & $\begin{array}{c}\text { IR } \\
\left(\mu g \mathrm{~g} \mu \mathrm{C}^{-1} \mathrm{~d}^{-1}\right)\end{array}$ & $\begin{array}{l}\mathrm{AE} \\
(\%)\end{array}$ & $\begin{array}{c}\mathrm{AR} \\
\left(\mu \mathrm{gC} \mathrm{g} \mathrm{C}^{-1} \mathrm{~d}^{-1}\right)\end{array}$ & $\begin{array}{c}\text { EPR } \\
\left(\mu g \mathrm{~g} \mu \mathrm{C}^{-1} \mathrm{~d}^{-1}\right)\end{array}$ & $\begin{array}{l}\text { GGE } \\
(\%)\end{array}$ & $\begin{array}{l}\text { EHS } \\
(\%)\end{array}$ \\
\hline Dun & & $0.099 \pm 0.063$ & $43.9 \pm 2.3$ & 0.043 & $0.022 \pm 0.011$ & 22 & $5.7 \pm 0.7$ \\
\hline$A m p$ & & $0.372 \pm 0.081$ & $40.6 \pm 1.1$ & 0.151 & $0.034 \pm 0.022$ & 9 & $43.9 \pm 3.9$ \\
\hline Pha & & $0.261 \pm 0.131$ & $49.2 \pm 1.6$ & 0.128 & $0.034 \pm 0.002$ & 13 & $35.3 \pm 3.7$ \\
\hline \multirow{3}{*}{ Dun $+A m p$} & Dun & $0.121 \pm 0.021$ & \multirow{3}{*}{$61.1 \pm 1.5$} & \multirow[t]{3}{*}{0.253} & \multirow{3}{*}{$0.153 \pm 0.029$} & \multirow[t]{3}{*}{37} & \multirow[t]{3}{*}{$36.4 \pm 4.9$} \\
\hline & $A m p$ & $0.293 \pm 0.147$ & & & & & \\
\hline & Sum & $0.414 \pm 0.168$ & & & & & \\
\hline \multirow[t]{3}{*}{ Dun + Pha } & Dun & $0.218 \pm 0.071$ & \multirow[t]{3}{*}{$29.3 \pm 0.4$} & \multirow[t]{3}{*}{0.140} & \multirow[t]{3}{*}{$0.067 \pm 0.007$} & \multirow[t]{3}{*}{14} & \multirow[t]{3}{*}{$37.3 \pm 2.1$} \\
\hline & Pha & $0.261 \pm 0.020$ & & & & & \\
\hline & Sum & $0.479 \pm 0.087$ & & & & & \\
\hline \multirow[t]{3}{*}{$A m p+P h a$} & $A m p$ & $0.280 \pm 0.131$ & \multirow[t]{3}{*}{$43.9 \pm 0.3$} & \multirow[t]{3}{*}{0.150} & \multirow[t]{3}{*}{$0.058 \pm 0.020$} & \multirow[t]{3}{*}{17} & \multirow[t]{3}{*}{$34.6 \pm 2.6$} \\
\hline & Pha & $0.061 \pm 0.019$ & & & & & \\
\hline & Sum & $0.340 \pm 0.123$ & & & & & \\
\hline
\end{tabular}




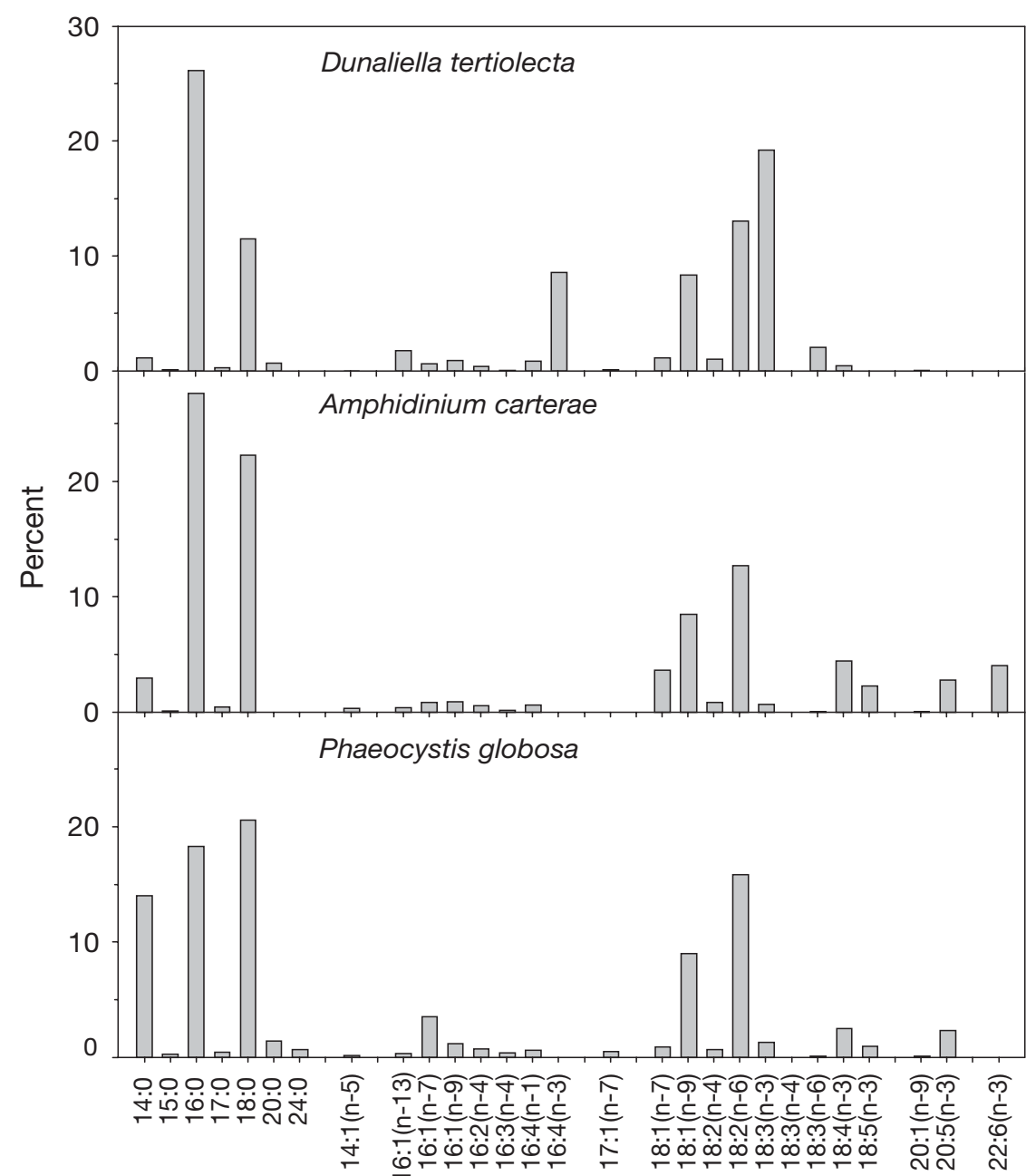

Fig 1. Distribution of fatty acids in the 3 algal diets as a percent of the total mass of fatty acids

(1) $18: 3(n-3), 16: 4(n-3), 16: 1(n-13)$, and 18:3(n-6)

(2) $22: 6(n-3), 20: 5(n-3)$, and 18:5(n-3)

(3) $16: 1(\mathrm{n}-7)$

The linear multiple regression analysis showed a significant positive correlation between EPRs and IRs of the 18:3(n-3) and 22:6(n-3) groups (Table 3). Using

Table 3. Acartia tonsa. Linear multiple regression analysis of EPR vs. ingestion rates (IR) and absorption rates (AR) of specific fatty acid groups. VIFs are variance inflation factors, a measure of the intercorrelation between variables

\begin{tabular}{|lrrrc|}
\hline & Coefficient $\pm \mathrm{SD}$ & $\mathrm{p}$ & $\mathrm{VIF}$ & Global ${ }^{2}$ \\
\hline $\mathrm{IR}_{\text {constant }}$ & $-2.76 \pm 0.45$ & $<0.001$ & & \\
$\mathrm{IR}_{18: 3(\mathrm{n}-3)}$ & $44.1 \pm 18.0$ & 0.027 & 1.35 & \\
$\mathrm{IR}_{16: 1(\mathrm{n}-7)}$ & $89.6 \pm 85.6$ & 0.312 & 1.32 & \\
$\mathrm{IR}_{22: 6(\mathrm{n}-3)}$ & $115.1 \pm 46.9$ & 0.027 & 1.41 & 0.400 \\
$\mathrm{AR}_{\text {constant }}$ & $-0.02 \pm 0.07$ & 0.796 & & \\
$\mathrm{AR}_{18: 3(\mathrm{n}-3)}$ & $24.3 \pm 6.75$ & 0.003 & 1.21 & \\
$\mathrm{AR}_{16: 1(\mathrm{n}-7)}$ & $28.6 \pm 35.9$ & 0.437 & 1.45 & \\
$\mathrm{AR}_{22: 6(\mathrm{n}-3)}$ & $78.3 \pm 17.9$ & $<0.001$ & 1.21 & 0.702 \\
\hline
\end{tabular}

this regression we were able to explain $40 \%$ of the variation in EPRs. Multiple regression tests are only possible with independent variables (fatty acid groups) with no significant intercorrelation, but judging from the size of the variance inflation factors the intercorrelation was low (Table 3). The correlation between EPRs and fatty acids became stronger when applying the AR data. Here we were able to explain $70 \%$ of the variation in EPRs with variations in fatty acid ARs (Table 3).

EHS varied significantly with IRs of the 16:1(n-7) and 22:6(n-3) groups and the regression could explain as much as $82 \%$ of the variation (Table 4 ). Unlike the regression of EPR we did not find stronger correlations when applying the AR data.

\section{DISCUSSION}

In the present study we demonstrated that EPRs in Acartia tonsa feeding on a mixed diet of the chlorophyte Dunaliella tertiolecta and the dinoflagellate Amphidinium carterae were higher than EPRs on any of the 2 species alone. Concurrently, we found significantly higher $\mathrm{AE}$ on this diet and we were able to explain $80 \%$ of the variations in EPR between the diets by variations in estimated ARs of 3 groups of unsaturated fatty acids in the gut.

Given the right food conditions Acartia tonsa can achieve EPRs of $50 \%$ body $\mathrm{C} \mathrm{d}^{-1}$ (recalculated from Jónasdóttir 1994). Considering the average female biomass of $4.6 \mu \mathrm{g} \mathrm{C}$, the egg production rates in our study

Table 4. Acartia tonsa. Linear multiple regression analysis of EHS vs. ingestion rates (IR) and absorption rates (AR) of specific fatty acid groups. VIFs are variance inflation factors

\begin{tabular}{|lrrrc|}
\hline & Coefficient $\pm \mathrm{SD}$ & $\mathrm{p}$ & $\mathrm{VIF}$ & Global R \\
\hline $\mathrm{IR}_{\text {constant }}$ & $0.04 \pm 0.04$ & 0.344 & & \\
$\mathrm{IR}_{18: 3(\mathrm{n}-3)}$ & $-0.11 \pm 1.63$ & 0.948 & 1.35 & \\
$\mathrm{IR}_{16: 1(\mathrm{n}-7)}$ & $53.6 \pm 7.73$ & $<0.001$ & 1.32 & \\
$\mathrm{IR}_{22: 6(\mathrm{n}-3)}$ & $28.9 \pm 4.24$ & $<0.001$ & 1.41 & 0.828 \\
$\mathrm{AR}_{\text {constant }}$ & $0.11 \pm 0.04$ & 0.018 & & \\
$\mathrm{AR}_{18: 3(\mathrm{n}-3)}$ & $-8.66 \pm 3.89$ & 0.042 & 1.21 & \\
$\mathrm{AR}_{16: 1(\mathrm{n}-7)}$ & $116.4 \pm 20.7$ & $<0.001$ & 1.45 & \\
$\mathrm{AR}_{22: 6(\mathrm{n}-3)}$ & $57.0 \pm 10.3$ & $<0.001$ & 1.21 & 0.747 \\
\hline
\end{tabular}


were all below $10 \%$ body $\mathrm{C} \mathrm{d}^{-1}$ on the monoalgal diets, comparable to other studies using similar poor quality diets (Verity \& Smayda 1989, Støttrup \& Jensen 1990, Kleppel \& Burkart 1995, Tang et al. 2001). The transformation of the ingested energy from the monoalgal diets was poor, with GGEs as low as $10 \%$ on all 3 monoalgal diets, proving the less than optimal quality of these diets. Turner et al. (2002) arrived at the same conclusion for Phaeocystis sp. eaten by Temora stylifera and Calanus helgolandicus. Discussing data from their own and 2 other studies (Verity \& Smayda 1989, Tang et al. 2001), Turner et al. (2002) concluded that copepods may well ingest Phaeocystis sp. at relatively high rates but the resulting egg production, and thus GGE, remains low; they also speculated that Phaeocystis sp. constitutes a poor food source due to the lack of certain fatty acids. The same has been suggested for Dunaliella tertiolecta (Støttrup \& Jensen 1990).

From the energy balance equation it is evident that the low EPRs on the 3 monoalgal diets were a direct consequence of AEs below 50\%. In comparison, Conover (1966a) reported AEs of natural zooplankton assemblages ranging from 41 to $87 \%$. Tang \& Dam (1999) reviewed literature data on carbon AE of herbivorous copepods and found AEs for carbon mostly above 60 to $70 \%$. More importantly, Conover (1966b) engaged in the first study of food quality effects on copepod AE. Here Calanus hyperboreus experienced AEs ranging from 40 to $72 \%$ on a range of different phytoplankton diets. A few other studies describe food quality effects on AE in copepods. Pagano \& Gaudy (1986) fed Eurytemora velox different diets consisting of natural plankton assemblages and a range of different algal species. Analogous to Conover (1966b), they found a negative relationship between AEs and ash content of the algal diets. However, one assumption for the method used in those studies is that only the organic (or non-ash) fraction of the food is affected by the digestive processes. Thus, the ash content is used directly in the calculation of AEs and any regressions between AEs and ash content will carry an inherent element of autocorrelation. Besiktepe \& Dam (2002) extracted AEs by comparing ingestion and egestion rates of carbon established by carbon:volume ratios of algal cells and faecal pellets and found AEs in Acartia tonsa around 10\% on the heterotrophic dinoflagellate Oxyrrhis sp. and the diatom Thalassiosira weissflogii, while the ciliate Uronema sp., and the autotrophic dinoflagellate Prorocentrum minimum generated AEs at $85 \%$.

Interestingly, both Conover (1966b) and Besiktepe \& Dam (2002) found AEs above $85 \%$ on Dunaliella sp., much higher than our values around $45 \%$. It is difficult to explain why AE values would deviate so significantly between studies but it may depend on differences in methodology. Ingestion and egestion rates of Acartia tonsa feeding on Dunaliella tertiolecta are often quite low, making accurate measurements of these parameters difficult (Støttrup \& Jensen 1990, Besiktepe \& Dam 2002, Thor et al. 2002). Furthermore, calculations of AEs on the basis of ash may be biased since Dunaliella sp. contains only small amounts of ash (Conover 1966b). On the other hand, radiotracers can be used to follow the fate of organic carbon down to quantities in the nanogram range. In all experiments the measured isotopic activities were well above background levels and highly reproducible. There is therefore no reason why we should refrain from using the data for dietary comparisons in our study.

Egg production rates increased by $100 \%$ on the Dun + Amp diet relative to the monoalgal diets. This kind of supplemental effect of mixed diets on copepod egg production has been observed previously (Kleppel \& Burkart 1995, Schmidt \& Jónasdóttir 1997) and a parallel study showed EPRs increasing from 0.03 to $0.10 \mathrm{~d}^{-1}$ in Temora longicornis when switching from the monoalgal diets to a mixture of Dunaliella tertiolecta and Amphidinium sp. (Koski et al. 2006). Since the ingestion rates in our study were not significantly higher on the Dun + Amp diet than on the monoalgal diets, the GGE on the Dun + Amp diet was over 3 times that on the monoalgal diets. This enhancement of GGE coincided with considerably higher $\mathrm{AE}$ and AR. It therefore seems plausible that EPRs increased at least in part as a result of increased absorption of organic carbon, and it appears that the effects of diet mixing set in already during absorption in the gut. This notion has been put forward previously by Mayzaud et al. (1998): They fed Acartia tonsa diatom (Thalassiosira weissflogii) and diatom detritus diets and recorded decreased AEs on the latter. Mayzaud et al. (1998) speculated that gut absorption in 'Acartia-type' copepods may be adapted to essential nutrients, in this case nitrogen/protein. Obviously this could also apply for other nutritional components like fatty acids.

Highly unsaturated fatty acids (HUFAs), especially the omega-3 (n-3) HUFAs, are important for the functioning of the cell membrane. Since these are not synthesised de novo by copepods they must be obtained from the diet. Of these HUFAs, the 22:6(n-3) and 20:5(n-3) fatty acids are essential for egg production in calanoid copepods (Jónasdóttir 1994, Shin et al. 2003, Arendt et al. 2005), hence the significant correlation of EPRs to IR and AR of the 22:6(n-3) fatty acid group. However, though Amphidinium carterae contained both 20:5(n-3) and 22:6(n-3), EPRs remained low on this diet; this suggests that EPRs in Acartia tonsa depend on additional food components. Based on the EPRs with the mixed diets it appears that Dunaliella tertiolecta could supplement $A$. carterae but not Phaeo- 
cystis globosa. A comparison of the algal fatty acids (Fig. 1) shows that this additional component could be either 18:3(n-3) or 16:4(n-3). These 2 fatty acids belonged to the same intracorrelating group with respect to IR, and the multiple regressions showed that ingestion and absorption of fatty acids from the 18:3(n-3) group was highly important for egg production. This is consistent with field observations by Hazzard \& Kleppel (2003). Interestingly, even though D. tertiolecta contained high amounts of $18: 3(n-3)$, the Dun diet did not induce high EPRs and the multiple regression showed the 22:6(n-3) group to be equally important for EPR. This group contained 20:5(n-3), 18:5(n-3) and 22:6(n-3). A. carterae contained both 22:6(n-3) and 20:5(n-3) whereas P. globosa contained only 20:5(n-3). Both algae contained 18:5(n-3). Thus, if indeed EPRs were enhanced by differences in the fatty acid contents of the diets, the logical extension is that simultaneous ingestion and absorption of 18:3(n-3) or 16:4(n-3) from $D$. tertiolecta and 22:6(n-3) from $A$. carterae caused the higher EPRs.

The copepod gut is probably evolutionarily adapted to absorption of essential nutrients, including essential fatty acids, and a higher content of these fatty acids in the diet could stimulate overall carbon AE. A study of the freshwater cladoceran Daphnia magna has shown that a higher content of nutrients, in this case phosphorous, may indeed stimulate overall carbon AE (DeMott et al. 1998). Experiments with dual-labelled $\left({ }^{14} \mathrm{C} /{ }^{32} \mathrm{P}\right)$ Scenedesmus acutus showed that carbon AE declined as the C:P ratio of the diet increased. Adding unlabelled P-deficient algae reduced the carbon AE for labelled P-sufficient algae, whereas adding unlabelled P-rich algae improved the carbon AE for labelled Pdeficient algae (DeMott et al. 1998). If this also applies for fatty acids in copepods, the increased EPR observed in our study could have been caused not only by fatty acid supplementation for biosynthesis, but also by the increased carbon AE triggered by ingestion of essential fatty acids on the Dun + Amp diet.

Egg hatching has been shown to depend on the availability of several fatty acids, particularly 20:5(n-3), 22:6(n-3), 18:3(n-3) and 18:4(n-3) (Lee et al. 1999). Dunaliella tertiolecta was devoid of both 20:5(n-3) and 22:6(n-3) and it is not surprising that egg hatching success was significantly lower on the Dun diet. With the multiple regression analysis we found that EHS depends on the 22:6(n-3) group and 16:1(n-7). Since EHS was significantly higher on all other than the Dun diet it is difficult to judge which of the fatty acids from the 22:6(n-3) group were responsible. Interestingly, we did not find any positive correlation between EHS and the IR or AR of the 18:3(n-3) group fatty acids. EHS may thus depend on any of $22: 6(n-3), 20: 5(n-3)$, or 18:5(n-3) and on 16:1(n-7).
The present study is the first of its kind, combining measurements of absorption with analysis of dietary fatty acid content. Since absorption measurements of specific fatty acids would involve individually labelled fatty acids, we used theoretical fatty acid ARs. Even though dietary fatty acids are not always absorbed equally well in the copepod gut (Hazzard \& Kleppel 2003) it is reasonable to assume that essential fatty acids would be preferentially absorbed in the gut. We found that 18:3(n-3) (or 16:4[n-3]) and 22:6(n-3) are essential for egg production and previous studies have shown that these are incorporated into copepods with high efficiency (recalculated from Hazzard \& Kleppel 2003). We therefore believe that any differential absorption would only strengthen the relationship we found between fatty acid ARs and EPRs. Thus, applying the estimated AE of fatty acids, has brought us one step closer to the elusive connection between diet composition in terms of fatty acids and egg production and hatching in copepods.

Acknowledgements. P.T. was supported by the Danish Natural Science Research Council (grant \# 51-00-0415) and the European Commission (contract \# HPMF-CT-2001-01110). M.K. was supported by the Academy of Finland and an Access to Research Infrastructure (ARI) grant (\# ARI.P.15) from Kristineberg Marine Research Station. K.W.T. was supported by a NorFA Mobility Scholarship (Norway) and a Carlsberg Foundation Scholarship (Denmark).

\section{LITERATURE CITED}

Arendt KE, Jonasdottir SH, Hansen PJ, Gartner S (2005) Effects of dietary fatty acids on the reproductive success of the calanoid copepod Temora longicornis. Mar Biol 146: 513-530

Besiktepe S, Dam HG (2002) Coupling of ingestion and defecation as a function of diet in the calanoid copepod Acartia tonsa. Mar Ecol Prog Ser 229:151-164

Calow P, Fletcher CR (1972) A new radiotracer technique involving ${ }^{14} \mathrm{C}$ and ${ }^{51} \mathrm{Cr}$ for estimating the assimilation efficiencies of aquatic primary consumers. Oecologia 9: 155-170

Conover RJ (1966a) Assimilation of organic matter by zooplankton. Limnol Oceanogr 11:338-345

Conover RJ (1966b) Factors affecting the assimilation of organic matter by zooplankton and the question of superfluous feeding. Limnol Oceanogr 11:346-354

DeMott WR, Gulati RD, Siewertsen K (1998) Effects of phosphorus-deficient diets on the carbon and phosphorus balance of Daphnia magna. Limnol Oceanogr 43:1147-1161

Frost BW (1972) Effect of size and concentration of food particles on the feeding behaviour of the marine planktonic copepod Calanus finmarchicus. Limnol Oceanogr 17: 805-815

Guillard RRL (1975) Culture of phytoplankton for feeding marine invertebrates. In: Smith WL, Chanley MH (eds) Culture of marine invertebrate animals. Plenum Press, New York, p 26-60

Hazzard SE, Kleppel GS (2003) Egg production of the copepod Acartia tonsa in Florida Bay: role of fatty acids in the 
nutritional composition of the food environment. Mar Ecol Prog Ser 252:199-206

Jónasdóttir SH (1994) Effects of food quality on the reproductive success of Acartia tonsa and Acartia hudsonicalaboratory observations. Mar Biol 121:67-81

Kiørboe T, Møhlenberg F, Hamburger K (1985) Bioenergetics of the planktonic copepod Acartia tonsa: relation between feeding, egg production and respiration, and composition of specific dynamic action. Mar Ecol Prog Ser 26:85-97

Kleppel GS, Burkart CA (1995) Egg-production and the nutritional environment of Acartia tonsa-the role of food quality in copepod nutrition. ICES J Mar Sci 52:297-304

Kleppel GS, Burkart CA, Houchin L (1998) Nutrition and the regulation of egg production in the calanoid copepod Acartia tonsa. Limnol Oceanogr 43:1000-1007

Koski M, Klein Breteler W, Schogt N (1998) Effect of food quality on rate of growth and development of the pelagic copepod Pseudocalanus elongatus (Copepoda, Calanoida). Mar Ecol Prog Ser 170:169-187

Koski M, Klein Breteler WCM, Schogt N, Gonzalez S, Jakobsen HH (2006) Life-stage-specific differences in exploitation of food mixtures: diet mixing enhances copepod egg production but not juvenile development. J Plankton Res 28:919-936

Lee HW, Ban S, Ando Y, Ota T, Ikeda T (1999) Deleterious effects of diatom diets on egg production and hatching success in the marine copepod Pseudocalanus newmani. Plankton Biol Ecol 46:104-112

Mayzaud P, Tirelli V, Bernard JM, Roche-Mayzaud O (1998) The influence of food quality on the nutritional acclimation of the copepod Acartia clausi. J Mar Syst 15: 483-493

Miller CA, Glibert PM (1998) Nitrogen excretion by the calanoid copepod Acartia tonsa: results of mesocosm experiment. J Plankton Res 20:1767-1780

Montagnes DJS, Berges JA, Harrison PJ, Taylor FJM (1994) Estimating carbon, nitrogen, protein, and chlorophyll from volume in marine phytoplankton. Limnol Oceanogr 39: 1578

Pagano M, Gaudy R (1986) Biologie d'un copepode des mares temporaires du littoral mediterraneen francais: Eurytemora velox. I. Nutrition. Mar Biol 90:551-564

Editorial responsibility: Kenneth Sherman (Contributing Editor), Narragansett, Rhode Island, USA
Payne MF, Rippingale RJ (2000) Evaluation of diets for culture of the calanoid copepod Gladioferens imparipes. Aquaculture 187:85-96

Rey C, Harris R, Irigoien X, Head R, Carlotti F (2001) Influence of algal diet on growth and ingestion of Calanus helgolandicus nauplii. Mar Ecol Prog Ser 216:151-165

Schmidt K, Jónasdóttir SH (1997) Nutritional quality of two cyanobacteria: how rich is 'poor' food? Mar Ecol Prog Ser 151:1-10

Sheppard G, Marlow CG (1971) The simultaneous measurement of ${ }^{51} \mathrm{Cr}$ and ${ }^{14} \mathrm{C}$ by liquid scintillation counting. Int J Appl Radiat Isot 22:125-127

Shin K, Jang MC, Jang PK, Ju SJ, Lee TK, Chang M (2003) Influence of food quality on egg production and viability of the marine planktonic copepod Acartia omorii. Prog Oceanogr 57:265-277

Støttrup JG, Jensen J (1990) Influence of algal diet on feeding and egg-production of the calanoid copepod Acartia tonsa Dana. J Exp Mar Biol Ecol 141:87-105

Tang KW, Dam HG (1999) Limitation of zooplankton production: beyond stoichiometry. Oikos 83:537-541

Tang KW, Jakobsen HH, Visser AW (2001) Phaeocystis globosa (Prymnesiophyceae) and the planktonic food web: feeding, growth, and trophic interactions among grazers. Limnol Oceanogr 46:1860-1870

Thor P (2000) Relationship between Specific Dynamic Action and protein deposition in calanoid copepods. J Exp Mar Biol Ecol 24:171-182

Thor P, Cervetto G, Besiktepe S, Ribera-Maycas E, Tang KW, Dam HG (2002) Influence of two different green algal diets on specific dynamic action and incorporation of carbon into biochemical fractions in the copepod Acartia tonsa. J Plankton Res 24:293-300

Turner JT, Ianora A, Esposito F, Carotenuto Y, Miralto A (2002) Zooplankton feeding ecology: Does a diet of Phaeocystis support good copepod grazing, survival, egg production and egg hatching success. J Plankton Res 24: 1185-1195

Verity PG, Smayda TJ (1989) Nutritional value of Phaeocystis pouchetii (Prymnesiophyceae) and other phytoplankton for Acartia spp. (Copepoda): ingestion, egg production, and growth of nauplii. Mar Biol 100:161-172

Submitted: August 19, 2005; Accepted: April 10, 2006

Proofs received from author(s): January 25, 2007 